\title{
Climatology of gravity wave activity during the West African Monsoon
}

\author{
P. Kafando ${ }^{1}$, F. Chane-Ming ${ }^{2}$, and M. Petitdidier ${ }^{3}$ \\ ${ }^{1}$ Laboratoire de Physique et de Chimie de l'Environnement, Université de Ouagadougou, Burkina Faso \\ ${ }^{2}$ Laboratoire de Physique de l'Atmosphère et des Cyclones, Université de la Réunion, Météo-France, CNRS, UMR 8105, \\ La Réunion, France \\ ${ }^{3}$ Centre d'Etudes des Environnements Terrestre et Planétaires, UMR 8639, France
}

Received: 22 May 2008 - Revised: 18 October 2008 - Accepted: 20 November 2008 - Published: 12 December 2008

\begin{abstract}
Gravity wave activity is analysed in the lower stratosphere using 6 year radiosonde data (2001-2006) above two meteorological stations in the West African tropical region such as Niamey $\left(13.47^{\circ} \mathrm{N} ; 2.16^{\circ} \mathrm{E}\right)$ and Ouagadougou $\left(12.35^{\circ} \mathrm{N} ; 1.51^{\circ} \mathrm{W}\right)$. Monthly total energy density of gravity waves is computed with temperature and horizontal wind perturbations to highlight the West African Monsoon period from June to September. Comparison with monthly total energy density calculated with temperature only supports that observed small-scale temperature and wind perturbations are mostly associated with gravity waves in the lower stratosphere especially for large values during the wet season. Above the two sites, monthly evolution of gravity wave total energy density reveals a maximum intensity of gravity wave activity in July during the West African Monsoon period. Indicators of convective activity such as mean Outgoing Longwave Radiation (OLR) and Tropical Rainfall Measuring Mission (TRMM) rain rates reveal to be adequate monsoon proxies to be compared to gravity wave energy intensity during the West African Monsoon.
\end{abstract}

Keywords. Atmospheric composition and structure (Middle atmosphere - composition and chemistry; Thermosphere composition and chemistry)

\section{Introduction}

Tropical Gravity Waves (GWs) are known to contribute to the coupling of the atmospheric circulation from the lower atmosphere to the upper atmosphere by the vertical transport of momentum, energy and to impact on chemical constituents distribution. In particular, GWs play a significant role in driving the residual stratospheric circulation, and the tropical middle atmosphere oscillations: the Quasi-Biennal

Correspondence to: P. Kafando

(petronille.kafando@univ-ouaga.bf)
Oscillation and the Semi-Annual Oscillation (Pfister et al., 1993; Vincent and Alexander, 2000). Many studies reveal that deep convection is an important source of GWs in the tropics (Alexander and Holton, 1997; Piani et al., 2000). Some GW climatologies had been performed using various types of instruments such as radiosonde, lidar and satellite in the troposphere and in the lower stratosphere (Allen and Vincent, 1995; Wang and Geller, 2003; Tsuda et al., 2000; Ern et al., 2004; Chane Ming et al., 2007) but few studies focused on the African tropical belt. Global maps of variation of GW potential energy in the Lower Stratosphere (LS), derived from the data of Global Positioning System/Meteorology (GPS/MET) satellites, suggest that atmospheric waves are actively generated by tropical convection (Tsuda et al., 2000). But for this study GPS/MET satellite data are missing in the African tropical belt. Ratnam et al. (2004) show a global coherence between the activities of GW with vertical wavelenths $<10 \mathrm{~km}$ in the LS, derived from Challenging Minisatellite Payload (CHAMP) satellite observation and from Outgoing Longwave Radiation (OLR) data in tropical regions. In particular strong GW activities are mostly related to deep convection over the landmass of Africa. However no evidence of GW activity is observed during the West African Monsoon (WAM) as opposed to observations of variance of GWs with vertical wavelengths $>10 \mathrm{~km}$ derived from radiance fluctuations observed by the Microwave Limb Sounder (MLS) experiment aboard the Upper Atmospheric Research Satellite (UARS) in the upper stratosphere (Jiang et al., 2004b). Differences in $\mathrm{GW}$ observation are attributed to observational filtering effect (Alexander, 1998) and averaging process for intermittent waves observed by satellites (Jiang et al., 2004a). For example, GPS analysis provides observations of slow GW with short vertical wavelengths while the MLS focuses on fast GW with long vertical wavelengths (Alexander and Barnet, 2007).

Published by Copernicus Publications on behalf of the European Geosciences Union. 

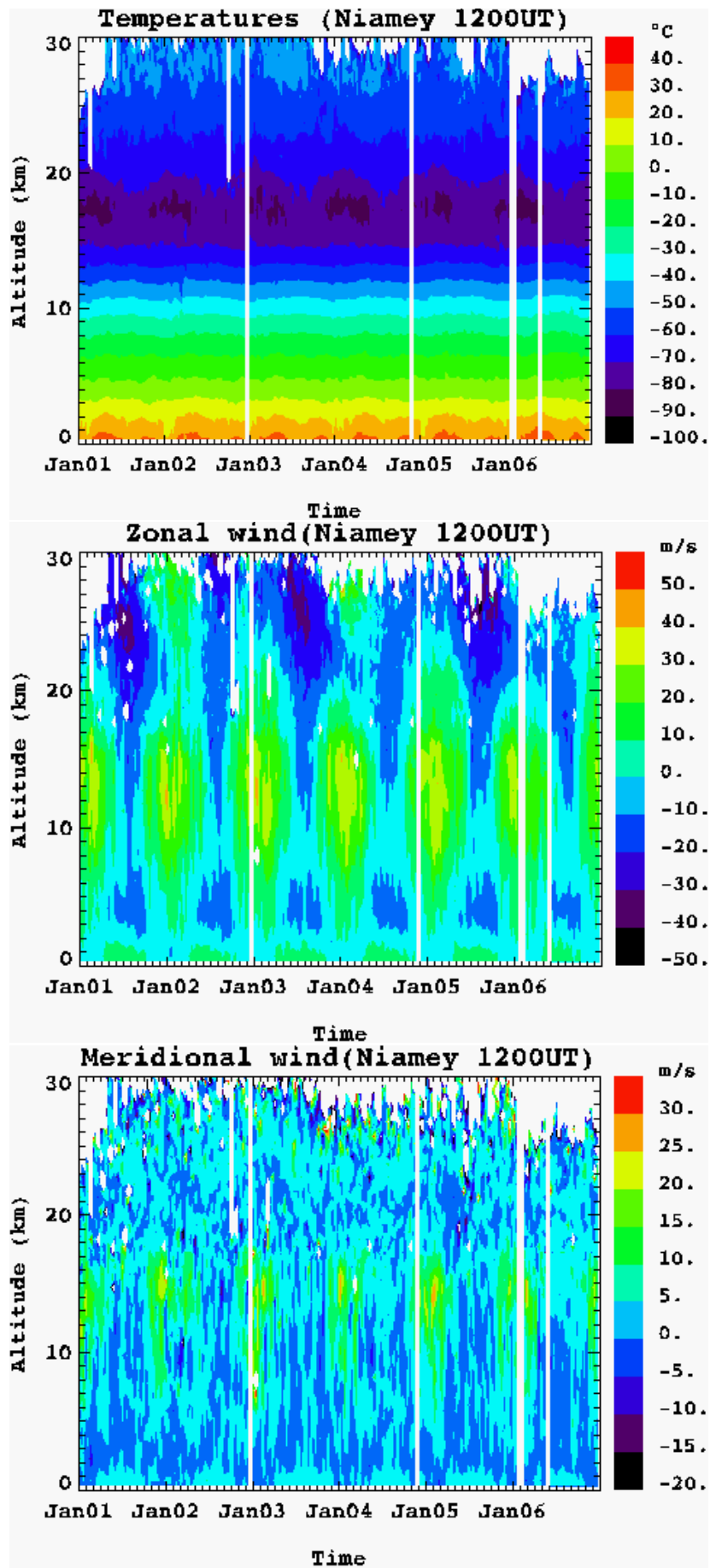

Fig. 1. Time-height cross section of 10-day mean (a) temperatures, (b) zonal and (c) meridional wind for Niamey 12:00 UT radiosoundings.

In this last study, strong GW activities are well-correlated with deep convection in monsoon areas and particularly at latitudes between $5^{\circ}$ and $25^{\circ} \mathrm{N}$ above the Africa.

Rainfall variability is a key element for socio-economical activities over West Africa. The rainfalls are controlled by a multi-scale interaction between severe convective systems and wave modes. Indeed large-scale atmospheric circulation over African equatorial and tropical areas results from the latent heat produced by deep convection. West Africa presents some specific geographical characteristics such as the Atlantic Ocean boundary at South and West and the Sahara desert at North which induce a complex atmospheric dynamics during the wet season (Hall and Peyrillé, 2006). Sultan and Janicot (2000) found that the InterTropical Convergence Zone (ITCZ) displacement shifts abruptly from $5^{\circ} \mathrm{N}$ to $10^{\circ} \mathrm{N}$ in June and a progressive southward displacement of the monsoon takes place in September-October period. Observations also reveal that the WAM is composed of intraseasonnal variability modes connected with the activity of equatorial waves (Mounier et al., 2004, 2007; Sultan et al, 2003). Since 2006, intensive observation periods are led in the framework of the African Monsoon Multidisciplinary Analyses (AMMA) international campaign to improve our understanding of the WAM dynamics such as the precipitating weather systems for weather forecasting (Redelsperger et al., 2006).

The present work analyses GW activity in the lower stratosphere in the West Africa tropical region using meteorological radiosonde datasets above Niamey $\left(13.47^{\circ} \mathrm{N} ; 2.16^{\circ} \mathrm{E}\right)$ and Ouagadougou $\left(12.35^{\circ} \mathrm{N} ; 1.51^{\circ} \mathrm{W}\right)$ in West Africa during the 2001-2006 period. A first climatology of GW energy densities above West Africa is discussed specially in relation with the convective activity during the WAM.

\section{Data and method}

\subsection{The dataset}

A six-year meteorological radiosonde dataset is analysed to study temperature and wind perturbations induced by GWs from 2001 to 2006 in sub-Saharian Africa above Niamey $\left(13.47^{\circ} \mathrm{N} ; 2.16^{\circ} \mathrm{E}\right)$ in Niger and Ouagadougou $\left(12.35^{\circ} \mathrm{N}\right.$; $\left.1.51^{\circ} \mathrm{W}\right)$ in Burkina Faso. $\mathrm{GW}$ analysis is applied on twice daily observations (00:00 and 12:00 UT, i.e. 01:00 and 13:00 LST) at Niamey and daily observations at Ouagadougou (12:00 UT). The two sites are located at quite the same latitude but distanced from about $500 \mathrm{~km}$. However some geographical differences exist between the two sites. The dataset includes 1677 (1487) radiosonde profiles at 12:00 UT (00:00 UT) at Niamey and 1736 radiosonde profiles at 12:00 UT at Ouagadougou.

Figure 1 shows time-height cross sections of 10-day averaged temperature and horizontal winds at Niamey 12:00 UT.

The West African zone is characterized by two main seasons:

- During dry season (October-May), highest surface temperatures up to $40^{\circ} \mathrm{C}$ are observed (Fig. 1a) and the Southward dusty wind known as the "Harmattan" is dominant from November to February (Fig. 1c). The 
Harmattan layer reaches the height of $4 \mathrm{~km}$ with an intensity of about $5 \mathrm{~ms}^{-1}$. The subtropical westerly jet is located from the middle to the upper troposphere. The maximum intensity of about $30-40 \mathrm{~ms}^{-1}$ is observed at 11-15 km height (Fig. 1b).

- During the WAM period from June to September, surface temperature decreases because of precipitations which refresh the atmosphere (Fig. 1a). The monsoon wind reaches the altitude of $1.5-2 \mathrm{~km}$ with meridional and zonal components of about $5 \mathrm{~m} \mathrm{~s}^{-1}$ and 10$20 \mathrm{~m} \mathrm{~s}^{-1}$, respectively (Fig. $1 \mathrm{~b}$ and c). The WAM period is also characterized by the seasonal reversal of wind in the lower atmosphere with the intensification of westerly wind at the surface between 20 and $30 \mathrm{~ms}^{-1}$ and the increase of the African Easterly Jet between 10 and $20 \mathrm{~m} \mathrm{~s}^{-1}$ at $2-6 \mathrm{~km}$ and the Tropical Easterly Jet between 10 and $20 \mathrm{~m} \mathrm{~s}^{-1}$ at $13-16 \mathrm{~km}$ (Fig. $1 \mathrm{~b}$ and c).

Some differences appear in surface temperature and wind during the WAM above the two sites. Niamey surface temperature is at most $2^{\circ} \mathrm{C}$ hotter than Ouagadougou and surface zonal wind intensity is at most $3 \mathrm{~m} \mathrm{~s}^{-1}$ stronger than Ouagadougou.

The mean tropopause height is located at $16.5-17 \mathrm{~km}$ (Fig. 1a). The mean lowest tropopause temperatures of $-81.2 \pm 0.7^{\circ} \mathrm{C}$ are observed during dry season at $17.4 \pm 0.2 \mathrm{~km}$. The WAM season is characterised by a lower tropopause height of $16.6 \pm 0.3 \mathrm{~km}$ and a warmer tropopause of $-78.8 \pm 0.7^{\circ} \mathrm{C}$. The Quasi-Biennal Oscillation (QBO) is visualized at height of $22-30 \mathrm{~km}$ in the stratosphere. The mean descent rate is ranging between 0.7 and $1 \mathrm{~km}$ per month and its period is estimated about $26.9 \pm 2.8$ months at heights of $26 \mathrm{~km}$ using Fourier analysis. The easterly phase of about $-40 \mathrm{~m} \mathrm{~s}^{-1}$ occurs during the monsoon period and is about twice stronger than the intensity of the westerly phase of about $+23 \mathrm{~m} \mathrm{~s}^{-1}$ (Fig. 1b).

\subsection{Data selection}

The Stratospheric Processes And their Role in Climate (SPARC) programme has proposed a Gravity Waves Initiative to estimate the activity of GWs from high-resolution meteorological radiosondes (Allen and Vincent, 1995). In the proposed procedure the first step consists of applying a quality control on temperature and horizontal wind values and a selection according to the vertical resolution $<1.5 \mathrm{~km}$. Profiles with a vertical resolution less than $300 \mathrm{~m}$ are regularly re-sampled using a cubic spline interpolation to derive mean profiles. The standard deviation $\sigma$ is calculated at every $500 \mathrm{~m}$ height for vertical profiles reaching the tropopause height. Temperature profiles with values between the annual mean and the standard deviation $\pm 3 \sigma$ interval at heights $<23 \mathrm{~km}$ are selected (Fig. 2). Indeed more than $70 \%$ of the total number of profiles reach the altitude of $23 \mathrm{~km}$ at the two

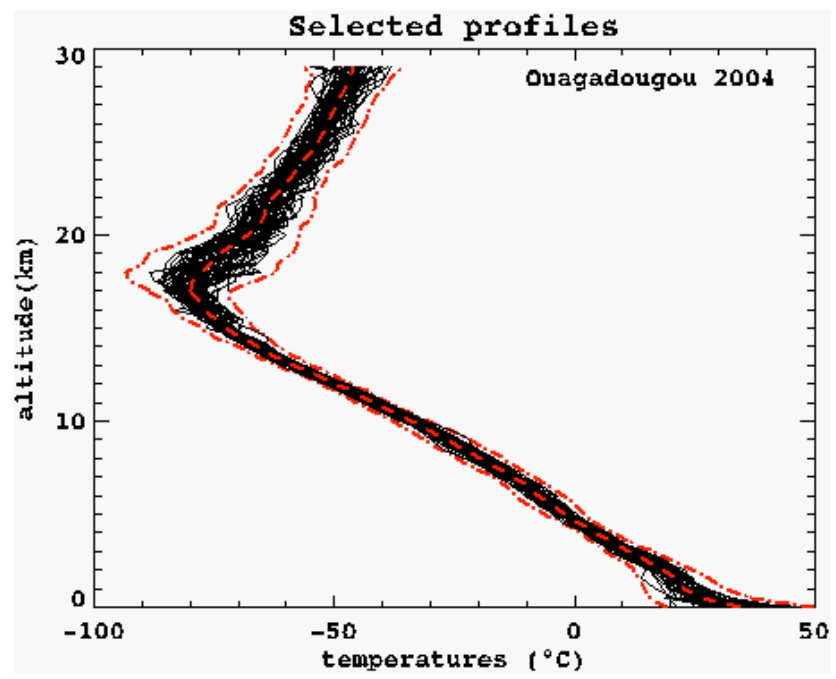

Fig. 2. Selected vertical profiles of temperature for heights less equal than $27 \mathrm{~km}$ at Ouagadougou in 2004.

sites during the studied period (Fig. 3). Monthly mean values, instead of annual ones, are used for the selection of the horizontal wind profiles because of the seasonal and interannual variation of wind such as the Quasi-Biennal Oscillation.

The activity of GWs is studied in the LS at heights between $19 \mathrm{~km}$ and $23 \mathrm{~km}$ for GW vertical wavelengths between $600 \mathrm{~m}$ and $4 \mathrm{~km}$ (Chane-Ming et al., 2007). The lower limit of $19 \mathrm{~km}$ is chosen to avoid perturbations induced by the tropopause region.

Monthly number of raw profiles varies between 80 and 143 at Niamey (00:00 UT), between 105 and 164 at Niamey (12:00 UT) and between 123 and 166 at Ouagadougou (12:00 UT). Percentages of total selected profiles are between $60 \%$ and $72 \%$ of the raw dataset. The dataset consists of 884 (1204) selected profiles at 00:00 UTC (12:00 UTC) for Niamey and 1192 selected profiles at 12:00 UTC for Ouagadougou. Thus monthly number of selected profiles varies between 40 and 90 for Niamey at 00:00 UTC with lowest values in February and August. Number of selected profiles varies between 70 and 120 with lowest values in January, February and November for Niamey at 12:00 UTC. Similar monthly number range is obtained for Ouagadougou. The lower values are between 79 and 90 in April and from July to November. Table 1 indicates the total number of selected profiles in the LS for each year.

\subsection{Energy computation}

Selected raw vertical profiles are oversampled every $100 \mathrm{~m}$ to process to $\mathrm{GW}$ analysis. Mean profiles of horizontal wind and temperature $(\bar{u}, \bar{v}, \bar{T})$ are estimated using a second-order polynomial fit and retrieved from raw vertical profiles $(u, v$, $T)$ to produce vertical profiles of perturbations (Allen and Vincent, 1995; Wang and Geller, 2003). Wang and Geller 
Table 1. Number of selected profiles and raw dataset in the Lower Stratosphere at heights between 19 and $23 \mathrm{~km}$ at Niamey (00:00 UT and 12:00 UT) and Ouagadougou (12:00 UT) from 2001 to 2006. Numbers of raw data are within parentheses.

\begin{tabular}{cccccccc}
\hline Year & 2001 & 2002 & 2003 & 2004 & 2005 & 2006 & Total number \\
\hline Niamey 00:00 UT & $102(243)$ & $111(159)$ & $129(184)$ & $216(290)$ & $161(307)$ & $165(304)$ & $884(1487)$ \\
Niamey 12:00 UT & $164(274)$ & $172(214)$ & $196(263)$ & $259(305)$ & $226(326)$ & $187(295)$ & $1204(1677)$ \\
Ouagadougou 12:00 UT & $189(314)$ & $267(323)$ & $188(256)$ & $253(327)$ & $158(307)$ & $137(209)$ & $1192(1736)$ \\
\hline
\end{tabular}

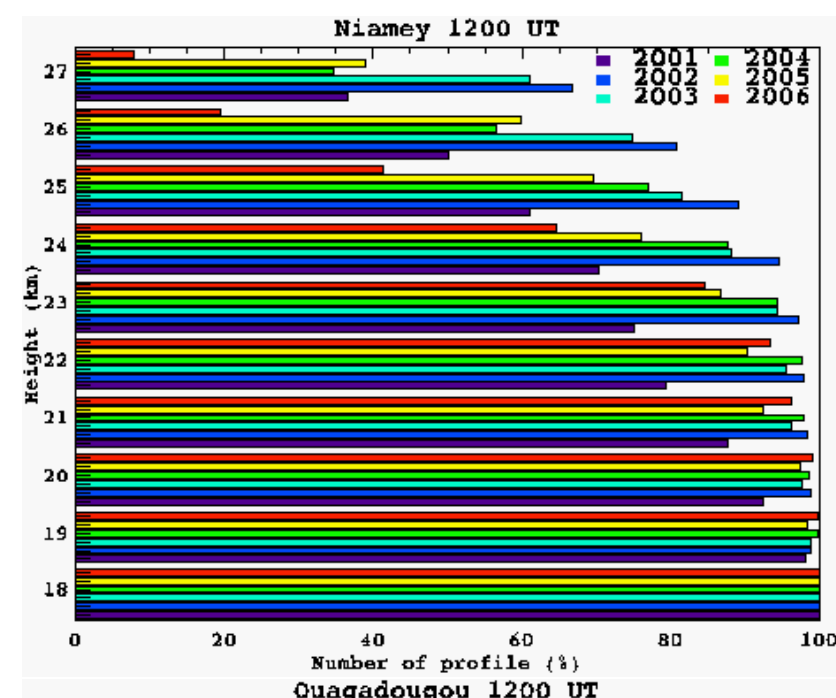

$\left(u^{\prime}, v^{\prime}, T^{\prime}\right)=(u, v, T)-(\bar{u}, \bar{v}, \bar{T})$

Total energy density $\left(E_{T}\right)$ is defined as the sum of kinetic and potential energy densities ( $K E$ and $P E$ ). It is computed to estimate GW activity (Vincent and Alexander, 2000).

$$
\begin{aligned}
& K E=\frac{1}{2}\left(\overline{u^{\prime 2}}+\overline{v^{\prime 2}}\right) \quad \text { and } P E=\frac{1}{2} \frac{g^{2}}{N^{2}} \overline{\hat{T}^{\prime 2}} \\
& E_{T}=K E+P E
\end{aligned}
$$

$g$ is the gravitational constant, $N$ is the buoyancy frequency, $\overline{\hat{T}^{\prime 2}}$ is the temperature perturbation normalized by the temperature background. The overbar on perturbations means an averaging over the altitude range.

Vertical wind is not measured by radiosonde and its fluctuations are considered not contributing significantly to $E_{T}$ and are in general neglected in the computation of $K E$.

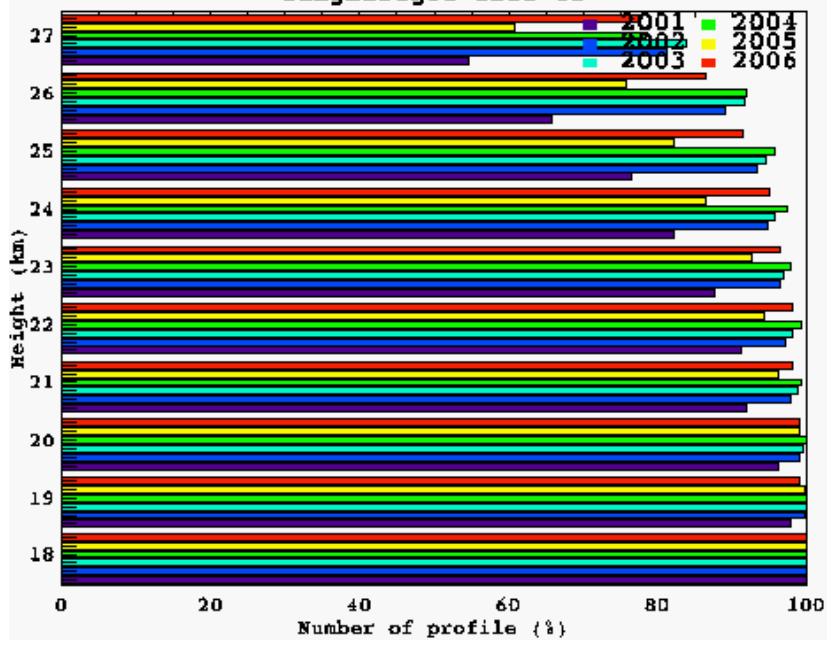

\section{Results and discussion}

\subsection{Evidence of gravity waves}

The hodograph analysis of horizontal wind perturbations applied on individual soundings shows the presence of elliptical structures which have characteristic of GWs above the two sites (Cot and Barat, 1986). Assuming the linear theory of GW, the total energy density $E_{T}$ can be estimated by using only the normalized temperature fluctuations (Allen and Vincent, 1995). A constant spectral index $p$ of 5/3 is used to compute the estimated total energy density.

The study shows a good correlation $>0.8$ between monthly mean total energy density $E_{T}$ and estimated energy density $E_{0}$ in tropical LS of the Indian Ocean basin. Figure 4 visualizes the linear regression between $E_{0}$ and $E_{T}$ for monthly and monthly mean values from 2001 to 2006 for Niamey at 12:00 UT. The dispersion of monthly mean $E_{T}$ from the linear regression is $<0.7$ and correlation coefficients are $\geq 0.75$ for the two sites. Factor coefficients and offsets of the linear regression are 0.4 (4.5) and 0.2 (5.7), respectively, for Niamey 00:00 UT (12:00 UT) and 0.7 (5.7) for Ouagadougou at 12:00 UT. Thus correlation coefficients indicate that observed temperature and horizontal wind perturbations above Niamey and Ougadougou in the LS are mostly produced by GWs especially for large total energy density in 
Table 2. Seasonal total, kinetic, potential GW energy densities in the Lower Stratosphere at heights between 19 and $23 \mathrm{~km}$ during the dry, monsoon, Transition 1 and Transition 2 periods. The first values refer to Niamey at 00:00 UT, the second ones to Niamey at 12:00 UT and the third ones to Ouagadougou 12:00 UT.

\begin{tabular}{lccc}
\hline Period & $E_{T}\left(\mathrm{~J} \mathrm{~kg}^{-1}\right)$ & $K E\left(\mathrm{~J} \mathrm{~kg}^{-1}\right)$ & $P E\left(\mathrm{~J} \mathrm{~kg}^{-1}\right)$ \\
\hline Dry season (November-April) & $8.6 / 8.6 / 8.5$ & $5.4 / 5.6 / 3.6$ & $3.1 / 3.1 / 4.9$ \\
Transition 1 (May-June) & $12.0 / 12.4 / 10.2$ & $8.7 / 8.9 / 5.0$ & $3.3 / 3.5 / 5.2$ \\
Wet season (July-August) & $15.3 / 15.4 / 12.7$ & $11.7 / 11.9 / 7.3$ & $3.6 / 3.4 / 5.3$ \\
Transition 2 (September-October) & $10.3 / 10.3 / 8.5$ & $7.2 / 7.4 / 4.1$ & $3.1 / 2.9 / 4.4$ \\
\hline
\end{tabular}

the wet season. Hertzog et al. (2002) showed that the discrepancy between $E_{0}$ and $E_{T}$ can be explained by an excess of near-inertial frequency waves in the LS. During the dry season, possible equatorial planetary waves, Kelvin and Rossby-gravity waves for instance, might be dominant.

\subsection{Seasonal variation of gravity waves}

The West African region at latitudes between $10^{\circ}$ and $18^{\circ} \mathrm{N}$ is mainly characterised by the WAM and dry period. Thus energy parameters are calculated for four periods: the monsoon period or the rainy period from July to August, the dry period from November to April, the periods before the monsoon from May to June (hereinafter called Transition 1) and just following the monsoon from September to October (hereinafter called Transition 2). Total, kinetic and potential energy densities are gathered in Table 2.

During dry season, total energy density is about $8.6 \mathrm{~J} \mathrm{~kg}^{-1}$. It increases during Transition 1 period to reach highest values of $15.5 \mathrm{~J} \mathrm{~kg}^{-1}$ and $12.7 \mathrm{~J} \mathrm{~kg}^{-1}$ during the WAM above Niamey and Ouagadougou respectively and decreases during Transition 2. Total energy ratio between monsoon and dry periods is equal to 1.8 and 1.5 for Niamey and Ouagadougou respectively. An abrupt change in total energy density values during dry season and Transition 1 is observed. As opposed, values during Transition 2 are closest to those during dry season. In addition total energy density has similar order of magnitudes above Niamey at 00:00 UT and 12:00 UT. This indicates the consistency of the dataset and the analysis. Comparison between total energy density over the two sites shows similar variation in intensity and a seasonal activity with a maximum during the WAM. The analysis of kinetic and potential energy densities also reveals consistent values at 00:00 UT and 12:00 UT at Niamey. Kinetic energy density mostly contributes to total energy density above Niamey. In contrast with Niamey, kinetic and potential energy densities have same order of magnitudes above Ouagadougou. Thus Table 2 shows evidence of a seasonal GW activity with two main periods: dry season and the WAM with an abrupt change during dry season and Transition 1. Fraction of upward propagating wave energy defined in Allen and Vincent (1995) is about 0.7 for Niamey. This indicates that sources of

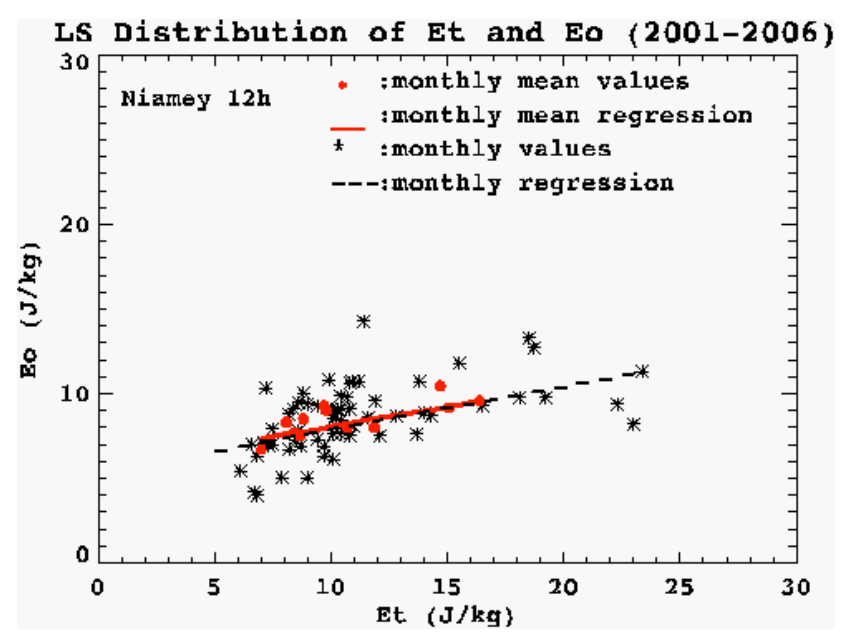

Fig. 4. Linear regression between $E_{0}$ and $E_{T}$ in the LS (19-23 km) for Niamey at 12:00 UT from January 2001 to December 2006.

GWs are located in the troposphere. Globally energy density values are consistent above the two sites.

3.3 Gravity wave activity and its relationship with the West African Monsoon

Monthly mean energy density weighted by monthly number of selected profiles has been calculated in LS from 2001 to 2006. Total energy density values vary between $8 \mathrm{~J} \mathrm{~kg}^{-1}$ and $20 \mathrm{~J} \mathrm{~kg}^{-1}$ (Fig. 5). An abrupt change in GW activity occurs in June with a relative increase in intensity $>60 \%$ from May to July. A progressive decrease is observed from July to October. Minimum and maximum values are ranging from 6 to $7.5 \mathrm{~J} \mathrm{~kg}^{-1}$ in December during dry period and from 15 to $19 \mathrm{~J} \mathrm{~kg}^{-1}$ in July during the WAM. Mean standard deviation is $<1.7 \mathrm{~J} \mathrm{~kg}^{-1}\left(<4.3 \mathrm{~J} \mathrm{~kg}^{-1}\right)$ for the October to April period (for the WAM). Total energy density is mainly composed of kinetic energy above Niamey and especially during the WAM above the two sites. Potential energy density is fairly constant $\left(<5 \mathrm{~J} \mathrm{~kg}^{-1}\right)$. Energy density values above Ouagadougou are consistent with those above Niamey in terms of magnitudes and variation but potential and kinetic 

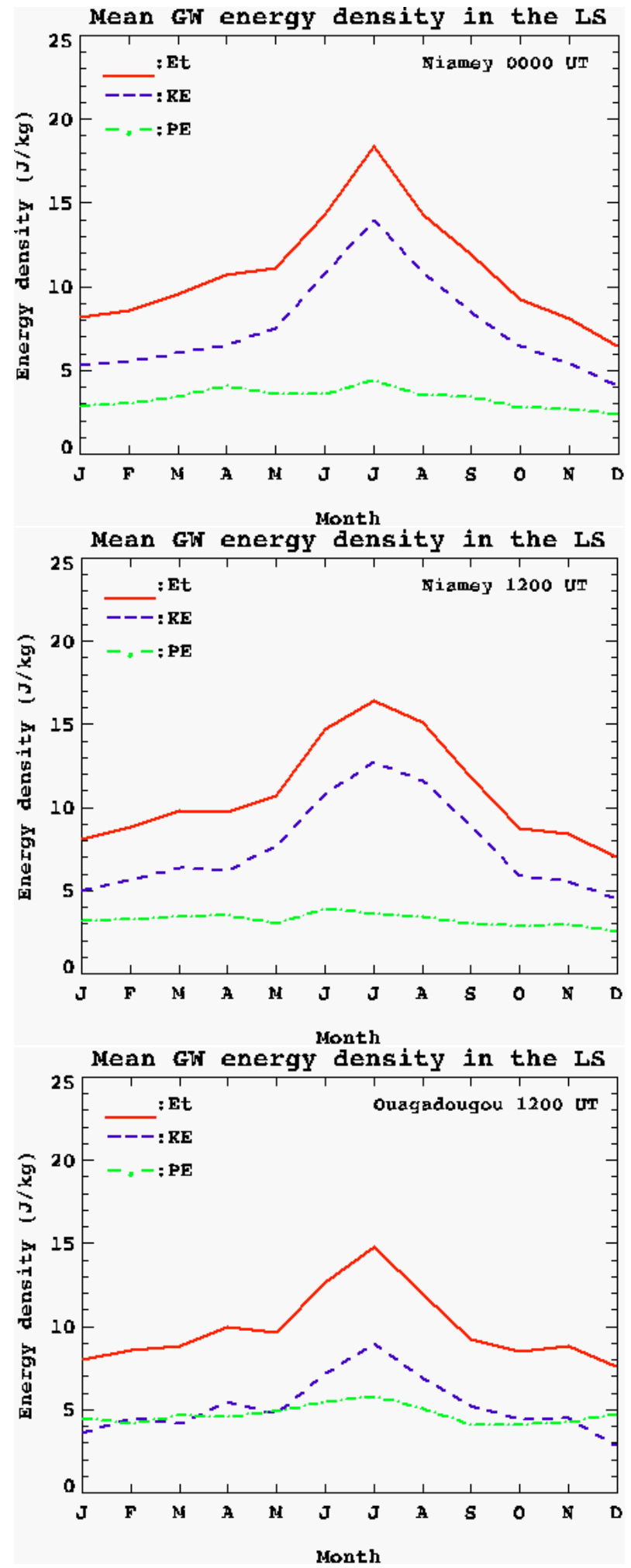

Fig. 5. Monthly mean total, potential and kinetic GW energy density at height of 19-23 km at (a) Niamey 00:00 UT, (b) Niamey 12:00 UT and (c) Ouagadougou 12:00 UT. Monthly mean values are weighted by monthly number of selected profiles from January 2001 to December 2006.
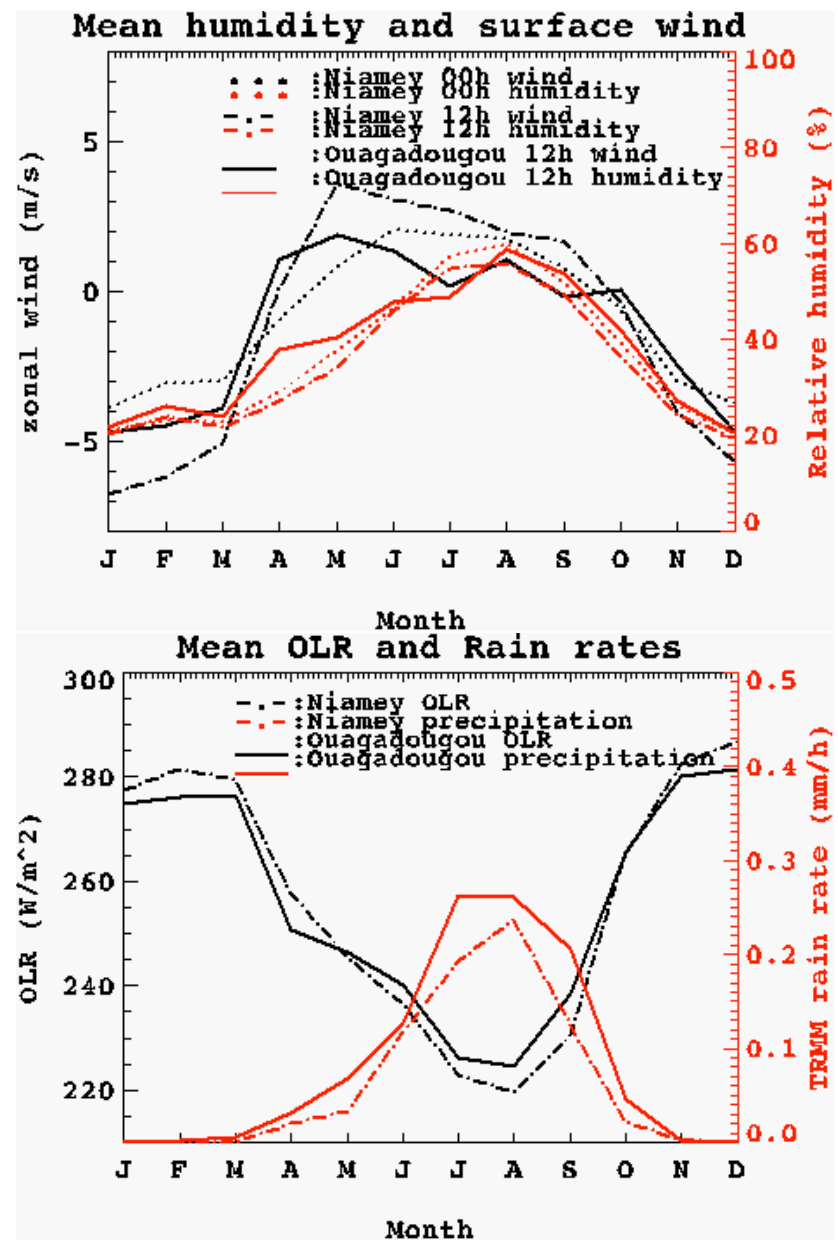

Fig. 6. Monthly mean WAM proxies from 2001 to 2006 above Niamey and Ouagadougou. (a) Averaged $1-5 \mathrm{~km}$ relative humidity and $0-1 \mathrm{~km}$ zonal surface wind. (b) Outgoing Longwave Radiation data and Tropical Rainfall Measuring Mission rain rate.

energy density values are of the same magnitudes, outside the monsoon period, above Ouagadougou.

Total energy ratio between the onset and pre-onset of the WAM in July and in June respectively are about 1.3, 1.1 and 1.2 for Niamey 00:00 UT, Niamey 12:00 UT and Ouagadougou at 12:00 UT, respectively.

Monsoon proxies are investigated to explore the relation with the intensity of GW total energy density. Figure $6 \mathrm{a}$ shows the evolution of monthly mean zonal wind surface and relative humidity intensities derived from radiosonde data and averaged on heights of $0-1 \mathrm{~km}$ and $1-5 \mathrm{~km}$, respectively. Westerlies which indicate the monsoon period are prevailing from April to October. They are observed from late March or mid-April and coincide with the intensification of relative humidity (28-34\%) above the two sites. The maximum of relative humidity $(60 \%)$ occurs in August above the sites whereas the surface wind peaks from May to June at 
Niamey and Ouagadougou. Maximum relative humidity is about $20 \%$ with prevailing easterly winds from November to March.

Tropical Rainfall Measuring Mission (TRMM) monthly rain rates with $0.25^{\circ} \times 0.25^{\circ}$ resolution and Outgoing Longwave Radiation (OLR) monthly data with $2.5^{\circ} \times 2.5^{\circ}$ resolution are extracted above Niamey and Ouagadougou as indicators of convective activity during the WAM. Evolution of OLR and rain rates are well consistent with the activity of convection over West Africa. A decrease in OLR accompagnied with an increase of precipitation is observed during the WAM (Fig. 6b). The monsoon pre-onset in May and onset in July are characterised by respective OLR values of $245 \mathrm{~W} \mathrm{~m}^{-2}$ and $222 \mathrm{~W} \mathrm{~m}^{-2}\left(245 \mathrm{~W} \mathrm{~m}^{-2}\right.$ and $227 \mathrm{~W} \mathrm{~m}^{-2}$ ) above Niamey (Ouagadougou). The two sites are high cloudiness region during the WAM from June to September with a well-defined peak of intensity localised between July and August. For the July-August period, standard deviation is $<5.7 \mathrm{~W} \mathrm{~m}^{-2}$ and $<5.1 \mathrm{~W} \mathrm{~m}^{-2}$, respectively, for Niamey and Ouagadougou. Convection over Niamey is slightly more important than over Ouagadougou during the June-September period and is associated with a precipitation rate $(0.24 \mathrm{~mm} / \mathrm{h})$ less than that at Ouagadougou $(0.27 \mathrm{~mm} / \mathrm{h})$. Standard deviation for the maximum precipitation rate is $0.09 \mathrm{~mm} / \mathrm{h}$ and $0.02 \mathrm{~mm} / \mathrm{h}$, respectively, for Niamey and Ouagadougou. Maximum GW activity is well-correlated with WAM proxies such as relative humidity $>45 \%$, precipitations $>0.1 \mathrm{~mm} / \mathrm{h}$ and OLR values $<240 \mathrm{~W} \mathrm{~m}^{-2}$ during the WAM above the two sites. Due to the well consistency of OLR data and rain rates with GW total energy density during the WAM, precipitation rates for example is chosen to investigate the relationship with the intensity of GW energy. Figure 7 shows linear regression between TRMM monthly precipitation quantity during the WAM from 2001 to 2006 and total energy density above Niamey and Ouagadougou. Rain quantity increases with GW activity. The strongest correlation is observed for Ouagadougou with a linear regression correlation coefficient of 0.62. Dispersion from linear regression is $<3.5 \mathrm{~J} \mathrm{~kg}^{-1}$. For the two sites, correlation coefficients are improved when considering large values of $\mathrm{GW}$ energy densities during the WAM.

\section{Discussion and conclusion}

Seasonal variation of GW energy density is consistent with previous observations in the tropics with regard to the activity of tropical convection (Allen and Vincent, 1995). Using radiosonde data at Coco Islands $\left(12^{\circ} \mathrm{S}-97^{\circ} \mathrm{E}\right)$ in the Southern Hemisphere, Vincent and Alexander (2000) found minimum total energy density of $9 \mathrm{~J} \mathrm{~kg}^{-1}$ in winter and maximum values ranging from 15 to $26 \mathrm{~J} \mathrm{~kg}^{-1}$ in summer at heights of 18-25 km. Tsuda et al. (2004) have also observed comparable magnitudes of potential energy density using CHAMP satellite data at $10^{\circ}$ latitude and longitudes between $80^{\circ} \mathrm{E}$

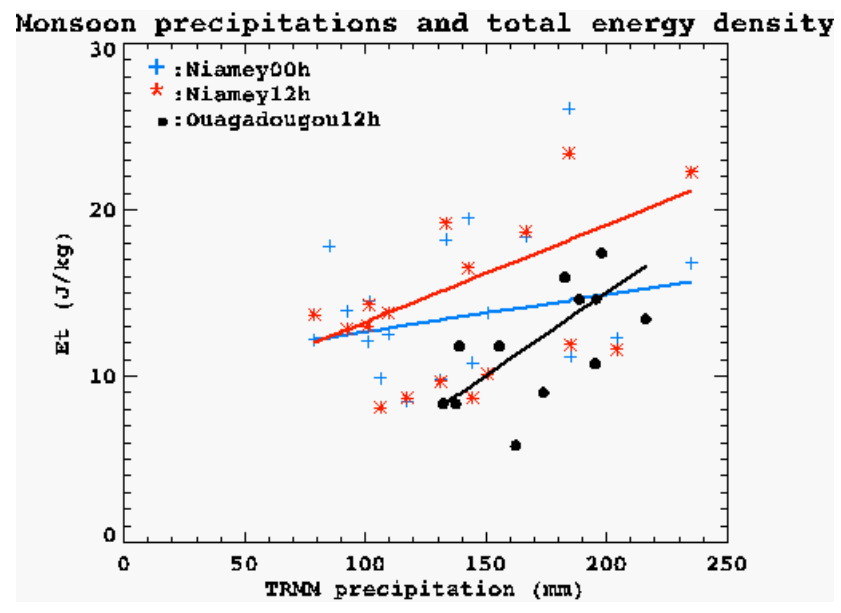

Fig. 7. Linear regression between TRMM monthly rain quantity and total energy density at heights between 19 and $23 \mathrm{~km}$ during the WAM from 2001 to 2006 for Niamey at 00:00 UT, Niamey at 12:00 UT and Ouagadougou at 12:00 UT.

and $180^{\circ} \mathrm{E}$ at heights of $20-25 \mathrm{~km}$ in the LS. More recently, Chane-Ming et al. (2007) confirmed similar seasonal variations and energy density values from 1998 to 2003 at heights between $19 \mathrm{~km}$ and $25 \mathrm{~km}$ in the LS above Tromelin Island $\left(15^{\circ} \mathrm{S}-54^{\circ} \mathrm{E}\right)$ in the Indian Ocean basin.

Tsuda et al. (2000) observed large potential energy density (up to $6 \mathrm{~J} \mathrm{~kg}^{-1}$ ) centered in the $25^{\circ} \mathrm{N}-25^{\circ} \mathrm{S}$ area with an enhancement near the Equator over deep convection regions in Africa at the altitude range of $20-30 \mathrm{~km}$ from November to February. Ratnam et al. (2004) also found globally a good correlation between GW variance derived form GPS/MET and OLR data. They showed fairly constant potential energy density values over the West Africa region with no obvious relation with the OLR activity during the WAM. Although MLS GW variances are mostly attributed to fast waves with vertical wavelengths $>10 \mathrm{~km}$, present results support observations of Jiang et al. (2004b) which showed a correlation between strong GW activity and the active convection from July to September 1994 during the WAM at heights of $28 \mathrm{~km}$ and $38 \mathrm{~km}$ over West Africa. In addition it is shown here that GW kinetic energy density mainly contributes to the activity of total energy density during the WAM.

The location of Niamey on the "Niger" river might influence the wind surface intensity, relative humidity and convection and consequently explain the difference in GW activity above Niamey and Ouagadougou. Indeed slightly higher precipitation and larger relative humidity are observed at Ouagadougou and Niamey respectively.

In summary, GW energy was studied in the West African region using six year meteorological radiosonde data from January 2001 to December 2006 above Niamey $\left(13.47^{\circ} \mathrm{N}\right.$; $\left.2.16^{\circ} \mathrm{E}\right)$ and Ouagadougou $\left(12.35^{\circ} \mathrm{N} ; 1.51^{\circ} \mathrm{W}\right)$ at heights of $19-23 \mathrm{~km}$ in the LS. Assuming GW linear theory, linear 
correlation between total energy density calculated from vertical profiles of temperature and wind perturbations and that calculated with temperature only revealed that most smallscale temperature and horizontal wind perturbations in the LS are mostly induced by GWs. Observations of elliptical structures using the hodograph method also confirmed the presence of GWs in the LS especially during the WAM. The examination of energy density reveals a seasonal GW activity with consistent values above the two sites during dry season and the WAM. The maximum GW activity with upward energy propagation occurred during the WAM period. Evolution of monthly mean total, kinetic and potential energy densities detailed the seasonal variation of the GWs. It was correlated with WAM proxies, especially cloudiness and precipitation which reveal to be good proxies to investigate the intensity of GW energy density during the WAM.

Thus tropospheric convection is a major source of GWs observed in the troposphere during the WAM. GW energy activity during the WAM is twice stronger than during dry season. An abrupt change in June and a progressive decrease from July to October in GW activity agree with the evolution of the ITCZ (Sultan and Janicot, 2000). In addition kinetic energy density mostly contributes to total GW energy density during the WAM period. Finally, monthly rain quantity as an indicator of the WAM can be estimated using a linear relation with total GW energy density in the LS during the WAM.

Further studies will extend the analysis to several meteorological stations in the West African area to investigate geographical variation. GW spectral and source characteristics will also be detailed.

Acknowledgements. The authors acknowledge sincerely the French Ministry of Foreign affairs for the financial support of P. Kafando stay at La Reunion Island University, and they also wish to thank the Wyoming University, the NOAA and the Goddard Distributed Active Archive Center for providing radiosonde observations, OLR data and TRMM rain rates, respectively.

Topical Editor F. D'Andrea thanks J. H. Jiang and another anonymous referee for their help in evaluating this paper.

\section{References}

Alexander, M. J.: Interpretations of observed climatological patterns in stratospheric gravity wave variance. J. Geophys. Res., 103, 8627-8640, 1998.

Alexander, M. J. and Barnet, C.: Using satellite observations to constrain parameterizations of gravity wave effects for global models, J. Atmos. Sci., 64, 1652-1665, 2007.

Alexander, M. J., Beres, J. H., and Pfister, L.: Tropical gravity waves activity and relationships to clouds, J. Geophys. Res., 105, 22299-22309, 2000.

Alexander, M. J. and Holton, J. R.: a model study of zonal forcing in the equatorial stratosphere by convectively induced gravity waves, J. Atmos. Sci., 54, 408-419, 1997.

Allen, S. J. and Vincent, R. A.: Gravity wave activity in lower atmosphere: seasonal and latitudinal variations, J. Geophys. Res., 100, 1327-1350, 1995.
Chane-Ming, F., Faduilhe, D., and Leveau, J.: Latitudinal and seasonal variability of gravity energy in the South-West Indian Ocean, Ann. Geophys., 25, 2479-2485, 2007, http://www.ann-geophys.net/25/2479/2007/.

Cot, C. and Barat, J.: Wave-turbulence interaction in the stratosphere: A case study. J.Geophys. Res., 91, 2749-2756, 1986.

Ern, M., Preusse, P., Alexander, M. J., and Warner, C. D.: Absolute values of gravity wave momentum flux derived from satellite data, J. Geophys. Res., 109, D20103, doi:10.1029/2004JD004752, 2004.

Hall, N. M. J. and Peyrillé, P.: Dynamics of the west African monsoon, J. Phys. IV, 139, 81-99, 2006.

Hertzog, A., Vial, F., Mechoso, C. R., Basdevant, C., and Cocquerez, P.: Quasi-Lagrangian measurements in the lower stratosphere reveal an energy peak associated with near-inertial waves, Geophys. Res. Lett., 29(8), 1229, doi:10.1029/2001GL014083, 2002.

Jiang, J. H., Eckermann, S. D., Wu, D. L., and Ma, J.: A Search for Mountain Waves in MLS Stratospheric Limb Radiances from the Winter Northern Hemisphere: Data Analysis and Global Mountain Wave Modeling, J. Geophys. Res. 109, D03107, doi:10.1029/2003JD003974, 2004a.

Jiang, J. H., Wang, B., Goya, K., Hocke, K., Eckermann, S. D., Ma, J., Wu, D. L., and Read, W. G.: Geographical distribution and interseasonal variablity of tropical deep convection: UARS MLS observations and analyses, J. Geophys. Res., 109, D03111, doi:10.1029/2003JD003756, 2004b.

Mounier, F. and Janicot, S.: Evidence of two independent modes of convection at intraseasonal timescale in the West African summer monsoon, Geophys. Res. Lett., 31, L16116, doi:10.1029/2004GL020665, 2004.

Mounier, F., Kiladis, G. N., and Janicot, S.: Analysis of the Dominant Mode of Convectively Coupled Kelvin Waves in the West African Monsoon, J. Climate, 20, 1487-1503, 2007.

Pfister, L., Scott, S., Loewenstein, M., Bowen, S., and Legg, M.: Mesoscale disturbances in the tropical stratosphere excited by convection: observations and effects on the stratospheric momentum budget, J. Atmos. Sci., 50(8), 1058-1075, 1993.

Piani, C., Durran, D., Alexander, M. J., and Holton, J. R.: A numerical study of three dimensional gravity waves triggered by deep tropical convection and their role in the dynamics of the QBO, J. Atmos. Sci., 57(22), 3689-3702, 2000.

Ratnam, M. V., Tetzlaff, G., and Jacobi, C.: Global and seasonal variations of stratospheric gravity waves activity deduced from the CHAMP/GPS satellite, J. Atmos. Sci., 61, 1610-1620, 2004.

Redelsperger, J. L., Thorncroft, C., Diedhiou, A., Lebel, T., Parker, D. J., and Polcher, J.: African Monsoon Multidisciplinary Analysis (AMMA): An International Research Project and Field Campaign, B. Am. Meteorol. Soc., 87(12), 1739-1746, 2006.

Sultan, B. and Janicot, S.: Abrupt shift of the ITCZ over West Africa and intra-seasonal variability, Geophys. Res. Lett., 27(20), 3353-3356, 2000.

Sultan, B., Janicot, S., and Diedhiou, A.: the West African Monsoon dynamics. Part I: documentation of intraseasonal variability, J. Climate, 16, 3389-3406, 2003.

Tsuda, T. and Nishida, M.: A global morphology of gravity wave activity in the stratosphere revealed by the GPS occultation data (GPS/MET), J. Geophys. Res., 105(D6), 7257-7273, 2000.

Tsuda, T., Ratnam, M. V., May, P. T., Alexander, M. J., Vincent, R. 
A., and MacKinnon, A.: Characteristics of gravity waves with short vertical wavelengths observed with radiosonde and GPS occultation during DAWEX (Darwin Area Wave Experiment), J. Geophys. Res., 109, D20S03, doi:10.1029/2004JD004946, 2004.

Vincent, R. A. and Alexander, M. J.: Gravity waves in the tropical lower stratosphere: an observational study of seasonal and interannual variability, J. Geophys. Res., 105, 17971-17982, 2000.
Wang, L. and Geller, M. A.: Morphology of gravity waves energy as observed from 4 years (1998-2001) of high vertical resolution U.S. radiosonde data, J. Geophys. Res., 108, 4196-4205, 2003. 